Nuestros clásicos 
(*) Javier Prado (1871-1921) fue una de las figuras más importantes y complejas que actuaron en los primeros años de este sielo. Hombre de vieorosa actividad pública (vinculada al Partido Civil, que llegó a presífir), ocupó alios cargos y funciones públicas (parlamentario, Ministro de Estado, Presidente de L Comisøon que prepuró el ptoyecto constitucional de 1920 ) ao descuidó sin embargo, sa relación con los altos circulos sociales y financieros, ni tampoce su pasión por la colección de objetos de arte, históricos $y$ afines, que lo llevaron a formar un riguísimo Museo. hoy en poder de la Universidad de San Marcos, a L que estuvo sierapre vinculado, conso alamno primero, profesor deqpués en variss cátedras, y màs adelante como Decano de b Facultad de Letras y, posteriormente, como Rector de b Universilad. Maestro de vasta influencia, incursionó en campos tan diversos como el derecho, b fiteratura, th historia y la filosofia, en todos los cuales hizo aportes de indtscutible importancia. Su paso pot el detecho, si bien fugat, fue decisivo. En 1889, frisando los 18 años, se gradúa de Bachiller en Jurisprudencia de la Univerlidad de San Marcos, con ana tesis sobre el método positivo en el derecho penal, que representa la introduceión en la universidad peruana del positivismo que tendria tan vasta influencia, no solo en Derecho, sino en Medicina y sobre todo en Letras (Fibosofia, Sicología, etc.). El positivismo (sobre todo en la vertiente de Spencer) tendría un gran auge a fines del siglo pasado, y se batíía en retirada a partir de 1915, con la participación del mismo Prađo, que al iqual que la mayoría de sus contempotíneos, terminé adhiriéndose al bergsonismo, De esta suerte, el introductor del positivismo universitario peruano, ya en su madurea, y antes de su trägica desaparición, terminaria orientindose a tas naevas corrientes idealisas.

Esta tesis javenil de 1889, tiene la siguiente ficha: Ea Método Positivo en el Derecho Penal / Tesis / que para optat el Grado de Bachiller / en la / Facultad de Jarisprudencia / presenta / Javier Prado y Ugarteche / Lima / Benito Gal-editor / Impreata y Librerias / Banco del Herrder 113 -Bodegones $42 / 1889 / \mathrm{pp}$. 156. La tesis, luego del respestivo gado, fue reeditada en 1890, sin variantes, salvo el prólogo de Carbos Lisson, que le fue añadido. Desde entonces a ha velto a ser pablicada, no obstante el tiempo transcurrido y ta importancis de la obra. Pot eso se reedita aqui, tomaindola del texto primigenio de 1889 , que gentilmente me ha proporcionado el Sr. Rahén Uzarteche, ahumno de la Facultad de Derecho y Cencias Politicas de la Universidad de Lima (Domingo García Helaunde). 


\section{El método positivo en el Derecho Penal (*)}

\section{Javier Prado y Ugarteche}

Señor Decano, Señores:

AS LUCHAS EN la esfera de la inteligencia, por medio del tibro y de - la cátedra, son más temibles que las sostenidas por los ejércitos en los campos de batalla. Estas, apoyadas en la fuerza, son, como el elemento en que se fundan, brutales y pasajeras; las luchas de las ideas, teniendo por arma el principio superior del hombre, la razón, son, por lo general, lentas y sordas, pero de fecundas y permanentes consecuencias.

$\mathrm{Si}$ esto es asi, nuestro siglo presenta un aspecto grandioso, pero sumamente desconsolador: es el siglo de las grandes convulsiones y contradicciones del pensamiento humano. Asistimos a una terrible crisis intelectual cuyo resultado nadie puede atinadamente prever. El ideal de los hombres del siglo XIX es contrario con su ciencia y con su filosofía. De aquí un profundo desequilibrio en las ideas, que se traduce en la duda cruel, en el desgarrador escepticismo, la tristeza y el abatimiento, la nostalgia de la vida, que sigilosa y traidoramente, corroen nuestras socie-. dades.

Espíritus ligeros, al ver torrentes de agua sustituyéndose a inmensas montaflas, acercando asi el genio del hombre continentes que se hallaban separados por la naturaleza; al observar máquinas a vapor cruzando la tierra y los mares; al asistir a las espléndidas Exposiciones de Europa, en las que el ánimo se encuentra anonadado, en frente a los innumerables descubrimientos que aumentan el bienestar material de la vida; supondrán, 
quizá, que el hombre del siglo XIX es feliz, porque cuenta con todos los medios para serlo; $y$ que la humanidad, rebosundo de orgullo, entra en plena edad de oro.

¡De cuán distinta manera piensa el médico observador y el filósofo consagrado al estudio de los problemas sociales! A uél, aleccionado por el trato diario de los enfermos, en las casas particu ares, asilos, hospitales, manicomios, nos enseñará, hondamente conmovido, el progreso aterrador de las perturbaciones del sistema nervioso, las que han resentido. de tal manera, el organismo, que ya hasta las mismas funciones fisiológicas no pueden realizarse sin producir graves alteraciones, sensaciones dolorosas, sufrimientos más o menos intensos.

La desgraciada familia de los neurópatas, en los siglos pasados, era muy reducida, presentándose siempre la enfermedad bajo una forma aislada y violenta; ahora ésta ha tomado un carácter, sin duda, más benigno, pero inmensamente más peligroso, por su variedad y generalidad, a tal extremo que nadie puede vanagloriarse, de una manera absoluta, de no sufrir su influencia. Las neurosis son el mal que caracteriza tristemente a la época actual: nuestra sangre se halla tan empobrecida, nuestra naturaleza tan débil y sensible, que para sostener el febril movimiento que demanda el siglo de la electricidad, necesitamos envenenar nuestro organismo por medio de toda clase de excitantes, a los cuales exigimos momentos de fuerza y vida ficticia, aun a trueque del consiguiente desfallecimiento o ruina de nuestro ser.

Este mal, cuya acción más implacable se ejercita en las pomposas ciudades de la vieja Europa, va transformando, de tal modo, el carácter de los individuos, que los hombres dia por día se vuelven melancólicos.

La universalidad de las enfermedades del sistema nervioso en nuestro siglo es ocasionada especialmente por causas morales, las que pueden resumirse todas en una ley sociológica: el doloroso esfuerzo de la inteligencia para adaptarse al nuevo medio social. Ella, en su vasta sintesis, comprende la lucha por la vida, que nunca se ha presentado tan feroz como al presente, a causa de la grandísima competencia abierta en todas las carreras por los principios de libertad; la emancipación del pensamiento, que ha permitido estudiar y criticar todas las ideas, teorías y dogmas; los placeres y sufrimientos vivisimos, que la misma complejidad de nuestras sociedades centuplica vertiginosamente, "haciendo que el hombre de nuestros días, en la edad en que sus antepasados comenzaban a serlo, no solamente haya desenvuelto más esfuerzos, realizado más trabajos, sostenido más 
luchas, sino que ha gustado más placeres, sưfrido más vicisitudes, experimentado más penas $y$ pesares".

Bajo este aspecto, pues, el mundo no se presenta tan risueño, ni ofrece un porvenir lleno de tan halagüeñas promesas, como, a primer golpe de vista, puede imaginar el incauto que lo observe por la superficie.

No son, sin duda, más consoladoras las palabras que arrancamos al filósofo, que sabe interpretar los fenómenos sociales. Lo primero que atrae, tristemente, su atención es el encono rabioso del combate intelectual sostenido entre el viejo Espiritualismo y el Materialismo contemporáneo; combate en el que cada contendiente representa una idea negativa: aquél el oscurantismo, éste el nihilismo; aquél ordenando el pensamiento humano que retroceda, jcomo si fuera posible a unos pocos hombres, con el sólo esfuerzo de sus brazos, hacer retroceder a una potente máquina, que marcha hacia adelante impelida por toda la presión del vapor!; éste proclamando la negación de todo principio religioso, filosófico y politico, jcomo si fuera posible a la inteligencia desarrollarse entre cadáveres y escombros!

$\mathrm{Y}$ al observar luego el filósofo, las consecuencias prácticas de esta implacable antinomia: ante el derrumbe de los antiguos ideales e instituciones; en presencia del socialismo incendiario, del desarrollo de las asociaciones de criminales, del aumento de los delitos y de los suicidios, verá algo más que simples fenómenos sin ninguna trascendencia; oirá los roncos y amenazadores ruidos interiores de las materias calcinantes que el volcán elabora en su seno, y que, muy pronto, convertidas en hirviente lava, envolverán a los pueblos, si es que los hombres no combaten, con pronto y eficaz remedio, a las enfermedades sociales. Como todavía éstas no se han dejado sentir fuertemente en nuestro suelo, tal vez piense alguno que es tiempo inútil el que se emplee aquí en estudiarlas; creyéndose bastante lejos de los lugares infestados se dejan arrullar tranquilos por el estéril egoismo, sin preocuparse del mal contagioso que aqueja a las naciones de Europa. ¡Fatal confianza! Los pueblos americanos, a pesar de la protección y aparente riqueza de su suelo, la juventud y fuerza de sus razas, viven, sin embargo, esclavizados por la corriente irresistible de la actividad intelecual de las sociedades del viejo Continente. No es, pues, sensato que descuidemos el estudio de los trascendentales problemas religiosos, filosóficos, sociales y políticos que en éste se desarrollan, Ellos interesan, especialmente, a las naciones que, como la nuestra, siendo una mezcla informe de elementos heterogéneos; $y$ no poseyendo, por tanto, el nivelado desarrollo intelectual, que requieren las instituciones políticas 
más avanzadas de la Europa para aclimatarse, crecer y dar lozanos frutos: al trasplantarlas, imprevisores, a nuestro suelo. nos hemos condenado nosotros mismos, a ser victimas de la más desconsoladora anarquia. a revolcarnos en el repugnante hecho donde se retuerce iuestra política confusa y versátil.

La cangrena que consume nuestro cuerpo político tiene ya raíces en nuestro cuerpo social.

Impresionado yo vivamente por estos problemas, al tener que presentarme, ante vosotros, a cumplir un deber reglamentario, he querido, olvidándome de las cuestiones de Derecho práctico, tratar una filosófica y de muy graves consecuencias positivas que corresponde, especialmente, a la Ciencia Criminal.

Al resolverme a emplear largas vigilias en este trabajo, me ha guiado por la idea de que no sólo es legitimo presentar ante esta ilustre corporación tesis, sosteniendo la bondad, error, insuficiencia u oscuridad de tal o cual título o artículo de nuestros códigos, sino que también tiene importancia para el Abogado y para la Sociedad estudiar estas legislaciones, en sí mismas, en su origen, y en sus fundamentos, ver, en conjunto, si el espíritu que las informa, corresponde con los adelantos de nuestra civilización.

Si no contara de antemano con vuestra benevolencia no hubiera escojido el tema de que voy a ocuparme, pues naturalmente tiene que ser mi estudio defectuoso, dada $\mathrm{mi}$ inexperiencia y mis conocimientos. Sirvame de disculpa mi buena voluntad.

Es tan intima la relación, que el notable desarrollo intelectual de nuestro siglo ha descubierto entre los diversos ramos del saber humano. que es ya imposible avanzar en el estudio de alguno de ellos, prescindiendo de la ayuda de los otros. La Ciencia Penal, por las difíciles y variadas materias que comprende, es una de las que más plenamente comprueba la excactitud de esta observación. Así la Filosofía (Psicología, Moral, Metafísica, Derecho Natural) ejerce sobre ella tan decidida influencia, que conforme a la solución que se dé a los problemas, que de ésta corresponden también a la Ciencia Criminal, se imprimirá el carácter a la obra, fijándose la escuela en la que se ha de colocar inmediatamente al escritor. que de tan importantísima materia trate. Por eso, reconociendo yo la 
estrecha unión de estas dos ciencias. me veo obligado a dividir mi trabajo en dos partes:

En la primera me ocuparé de algunos conceptos filosóficos y del método experimental en general, ideas que considero absolutamente indispensables para resolver el tema de mi disertación. En la segunda procuraré hacer ver la necesidad del método positivo en la Ciencia Penal, apoyándome en lo anteriormente expuesto, y en las consecuencias prácticas que aquí deduciré.

De la apremiante necesidad de precisar y separar los diversos partidos, ha nacido en la ciencia del Derecho, en estos últimos tiempos, la denominación genérica de Escuela Clásica, para comprender bajo su bandera a todos los jurisconsultos que defienden la existencia de un Derecho absoluto y eterno, conocido a priori; $y$ que empleando luego el método deductivo, derivan de aquél las leyes que han de regir a los pueblos, leyes a que se debe exigir, sean manifestaciones de la justicia absoluta e intrínseca. Se ha dado a esta teoria el título de Escuela Clásica por su exclusivo remoto origen, y por gozar, expresándome en términos escolásticos, del prestigio de la prueba de autoridad.

Como se observa a primer golpe de vista, la Escuela Clásica parte de una afirmación: el conocimiento que tiene el hombre de un conjunto de verdades absolutas. Este concepto trascendental no es sino la solución metafísica del problema que planteo magistralmente el filósofo Koenisberg. Séame, sin embargo, permitido rechazarlo, apoyándome en las conquistas de la filosofía contemporánea, que proclama como principio director en todas sus investigaciones, la relatividad de nuestros conocimientos.

La Escuela Clásica al sostener teorias a priori, abstractas e invariables, sobre el Derecho se pone en pugna con la Ciencia y la Historia; al volverse esencialmente metafisica e idealista rifie con la práctica y la experiencia. Ella se imagina poseer la verdad absoluta e inmutable. ¡Vana quimera! Nuestra limitada inteligencia sólo puede conocer lo fenomenal, no lo esencial. Los noumenos de Kant se hallan fuera del alcance de nuestra mezquina razón. La verdad, definida por la Metafisica, como "la conformidad de la idea con el objeto" no existe para el hombre, La verdad, para nosotros, no es sino la correspondencia exacta entre el orden 
de las ideas y el orden de las cosas, de manera que el encadenamiento del pensamiento se adapte y coincida con el movimiento de los fenómenos. Nuestras percepciones no nos ensenan los objetos tales como ellos son, sino en relación con nosotros; su verdad no es de semejanza sino de correspondencia. Cuando las relaciones subjetivas internas se adaptan exactamente a las relaciones objetivas externas, entonces hay verdad; en caso que no coincidan hay error. A la inteligencia humana, por más que se le alambique, sólo le es dado percibir cosas simultáneas y consecutivas: coexistencias y sucesiones; sólo puede conocer lo finito y lo relativo. Pensar es condicionar, si se eliminan las condiciones no hay pensamiento.

"Todo lo que sabemos de sujeto y objeto, espiritu y materia, dice el primer filósofo contemporáneo. Herbert Spencer, no es más que lo que cada uno de esos términos contiene de particular, de múltiplo, de diferente, de fenomenal" 1 . Asi ya la ciencia ha rechazado como prejuicio vulgar, la suposición de que el Universo es tal como lo percibimos. Si nuestra naturaleza cambiara nuestras percepciones serían del todo distintas. "La luz con sus miriadas de formas y de colores, el sonido con sus miles de aspectos son el ropaje con que nosotros vestimos el mundo; la naturaleza en su soledad insensible es eterno silencio y tinieblas eternas" 2 .

El conocimiento que tenemos de los seres, tanto físicos como morales, no es sino un conocimiento de relaciones, de referencias, como diria Bernard; y siendo estas variables, aquel también lo es. El metafísico que. creyendo haber descubierto principios abstractos, deduce de ellos consecuencias, que proclama necesarias e invariables, es digno de lístima por su funesta obsecación: las causas y las verdades primeras, la realidad objetiva, el principio y el fin de las cosas, la razón y las leyes esenciales de ellas serán siempre una eterna incógnita que atormentará el insensato orgullo del hombre.

La única ciencia cuyas leyes revisten un carácter de certidumbre absoluta son las matemáticas. La razón es obvia: Las matemáticas tienen por objeto el estudio de principos ideales, no reales; las condiciones que aquellas establecen son únicamente lógicas; no necesitando del mundo fenomenal, la inteligencia, cuando descubre o reconoce un axioma matemático, representa las relaciones de las cosas en condiciones de simplicidad 
ideal; así al decir un matemático: 3 y 2 son 5 , los tres ángulos de un trangulo son iguales a dos rectos. A es igual a $\mathrm{A}$, ha establecido princinios verdaderos absolutos, porque, apartándose de la realidad, comple;s y relativa, contienen ellos leyes lógicas de sencillez perfecta. Si nucstra razón pudiera concebir la unidad intrínseca de las ciencias naturales y morales, entonces los principios que sobre éstas ella enseñara serian también absolutos. Pero tal cosa es desgraciadamente imposible. Así nos dice la autorizada voz del gran Bernard "Cuando hacemos una teoria general de nuestras Ciencias, la única cosa de que estamos ciertos es, que todas estas teorías son falsas absolutamente hablando. No son más que verdades parciales y provisionales, que nos son necesarias como gradas sobre las que descansamos para avanzar en la investigación; no representan sino el estado actual de nuestros conocimientos..."3.

Este carácter relativo de nuestras ideas se observa aún más ostensible en las ciencias morales, a causa de la compleja variabilidad de los fenómenos que éstas comprenden. Sabido es que el estudio del hombre moral, en sus diversas manifestaciones, se funda en la observación interna y subjetiva. Cuando algunas inteligencias superiores, como la de Compte o Broussais, cegadas por ideas sistemáticas, han llegado a negar este principio evidente, debemos reconocer, una vez más, la falibilidad de la razón humana. No, la condición absoluta para descubrir y juzgar los hechos del espirtu es la Conciencia. La Materia será siempre impotente para descifrar los misterios del Pensamiento. Aś́ lo enseñan, no sólo profundos filósofos cient ificos como Herbert Spencer, Bain, Levves, Lotze, Ribot y Fouillée, sino fisiólogos tan notables como Bernard, Ferrier, Dubois-Raymond, patologistas como Virchow y sabios naturalistas del peso de un Tindall. ${ }^{4}$ Ninguna investigación objetiva psicofísica, ningún escalpelo del anatomista, ningún microscopio del histólogo, ningún alambique del químico, ningún aparato del fisiólogo, por más maravillosamente que pueda ser para escudriñar un hecho psicológico por su lado externo y fisiológico, no nos ensefará jamás, dice el reputado escritor Pedro Siciliani, lo que es un sentimiento, una emoción, una sensación, un deseo, una pasión, una representación, un recuerdo, un juicio, un acto deliberativo y así consecutivamente. 4

A la observación psicológica tienen pues que recurrir todas las

3 Cladio Bernard: Introducción al estudio de la medicina experimental; trad. esp. del Dr. A. Espina y Capo, 1880.

4 P. Siclilani: Prolégoménes a la psychogénie moderne;trad, franc, de A. Herzen, 1880. 
ciencias, que, como ti Derecho, procuran interpretar y reglar los fenomenos sociales. Pero ¿de que modo se debe proceder en esta observación? ¿Qué vałor encierran sus afirmacioncs? Veämoslo.

La conciencia es verdadera al darnos cuenta, intuitivamente, de los fenómenos de auestro espiritu; asi cuando nos dice, que sentimos, que pensamos, que queremos, se convierte en criterio infalible: reviste igual fuerza y certidumbre cuando nos manifiesta los objetos del mundo exterior en relación con las sensaciones que nos han producido. Pero, si, queriendo hacerla salir de su carácter individual. tratamos de convertir el sentido intimo, según la expresión de la Escuela Escocesa, en criterio científico evidente, $y$, apoyándose sólo en su testimonio subjetivo, formulamos reglas y principios objetivos y generales. entonces ella entra en un terreno escabroso y movedizo. en el que casi forzosamente tiene que tropezar y caer.

Los partidarios del método introspectivo en la ciencia del Derecho, para explicar el tránsito de la observación particular al principio universal y absoluto, razonan del modo siguiente: Todos los seres tienen un fin de llenar, y por tanto están sujetos a una ley. Esta ley será la misma para seres de igual naturaleza. Ahora bien, replegándonos en nuestra conciencia, observamos, que en ella se hallan grabadas las ideas del bien y del mal, de lo justo y de lo injusto, del mérito y del demérito, del premio y del castigo; $y$ como las mismas causas producen los mismos efectos. poseyendo los hombres igual naturaleza. por la ley de la analogia se deduce. que todos tienen inculcados idénticos principios, y por tanto que aquellas ideas son universales. $\mathbf{Y}$, continuando el razonamiento, concluye, que no sólo son universales, sino también invariables. puesto que la naturaleza humana ha sido siempre la misma.

Pero no bastaba esto, era preciso, aún justificar la verdad y justicia que encerraban aquellas leyes. En parte se alcanzaba tal intento, manifestando que se hallan en relación necesaria con nuestro fin, o sea con nuestro bien; pero como este concepto, aunque teóricamente exacto, es de difícil interpretación positiva, se recurrió a un verdadero Deus ex machina, $y$ aparece el Ser Supremo imprimiendo en la conciencia de cada hombre los principios inmutables del bien y del mal, del derecho y del delito.

¡He aquí el modo como se ha llegado a dar una forma de verdad y de justicia intrínseca a los preceptos de los hombres! Merced. pues, al procedimiento a priori, esencialmente subjetivo, aparece el Derecho natu- 
ral o filosófico proclamando dogmáticamente sus teorias como verdaderas y justas en si mismas: sobre estas concepciones ontológicas, sobre estos entes jurídicos. han levantado luego los jurisconsultos clásicos todo el edificio de la ciencia del Derecho.

Naturalmente al afiliarse a semejante teoría, inteligencias tan eminentes, como las que registra la bibliografia de la Escuela del principio fundamental ha tomado diversos aspectos, y se ha robustecido por originales y sutilisimas especulaciones.

Pero, por más grande que sea el respeto que se merezcan estos distinguidos jurisconsultos, es necesario decir, con toda la franqueza que da la firme convicción, que sus sistemas han caducado, porque la Filosofía y la Ciencia contemporánea han dado ya por tierra con la base que los sustentaba.

Según las prescripciones de la lógica, toda investigación para ser legitima tiene que recorrer tres términos: una observación, una hipótesis o conjetura y una comprobación o verificación. El método introspectivo. como lo han reparado notables filósofos, se detiene en el segundo grado. Los subjetivistas, llegando a la hipótesis, con tal que ella sea racional, y por tanto verosimil, creen haber descubierto la ley; $y$ entonces, subyugados por ella, en lugar de convencerse de la pureza de su temple, haciéndola soportar la rudo experimento de los hechos, la formulan a priori de un modo absoluto, encadenando así dogmáticamente a la rebelde realidad la que, a su vez. la desmiente con su brutal lógica. Los metafisicos en su modo de ver las cosas se parecen a los antiguos astrólogos: éstos se imaginaban hacer girar todo el vast ísimo sistema celeste alrededor de nuestro mezquino planeta. de la misma manera y con igual resultado con el que aquéllos pretenden encerrar la exhuberante y complejisima realidad en unas cuantas estrechas leyes a priori.

Antes de pasar adelante, creo de mi deber hacer una aclaración. Completamente lejos de mi ánimo se halla desconocer el valor general y necesario de algunas verdades. Así considero tan ciertas las leyes de la unidad, de la causalidad y de la finalidad que rigen a todos los seres, que $\sin$ ellas no concibo la existencia del Universo; pero cuando la metafísica amolda la Naturaleza a sus concepciones ontológicas a priori. en lugar de deducir esas leyes del estudio de la Naturaleza, cambiando así el carácter inmanente y experimental de ellas, en un sentido trascendental y abstracto, se convierte en una hipótesis falaz. La metafísica, no como la ciencia que comprende la mayor generalidad de nuestros conocimientos, tendiendo a la unificación científica de ellos, sino como el sistems filosó- 
fico de las razones ûltimas de las cosas, de las jdeas absolutas. de las causas trascendentales, es, permitidme Señores la crudeza de la frase, la más engañosa teoría sustentada por la soberbia humana, ¿Sabe clla, por ventura, algo cierto de lo que es el Ser y la Esencia, el Espiritu y la Materia, la Vida y el Movimiento? ¿Cómo nos prueban su verdad todas las gigantescas y opuestas concepciones, que desde los viejos Indios hasta Hegel y Schopenhauer, han tratado de interpretar el origen y naturaleza de las cosas? ¿No nos enseña, acaso, la Historia, que hay tantas metafísicas como filosofos, viniendo a convertirse aquella ciencia en un continuo proceso de suicidios, según la gráfica expresión de Herbert Spencer? Concluyamos: La metafisica trascendental ${ }^{5}$ significando la satisfacción de la necesidad imperiosa en todo hombre, de querer explicarse lo desconocido y misteriosa, representa, sin duda, una aspiración legítima de nuestra naturaleza racional. Esta curiosidad y anhelo natural hará que ella. como creencia subjetiva, nunca muera; pero al querer la vanidad del hombre transformar la intuición, más o menos fundada, en sistema filosófico, de verdad absoluta, crea un puro dogmatismo sin ninguna consistencia.

Hecha esta salvedad, y concretándome a la ciencia del Derecho. tropezamos a los pocos pasos con lo efímero de los principios abstractos. deducidos únicamente por la investigación subjetiva. Se díce: observando nuestra conciencia, notamos que en ella se hallan impresas las ideas de lo bueno y de lo malo, de lo justo y de lo injusto, del mérito y del demérito, del premio y del castigo. De la observación se pasa luego a la hipótesis de que todos los hombres tienen grabados los mismos principios porque todos poseemos igual naturaleza; y satisfechos los que proclaman el método subjetivo con su ley de analogía, se detienen ante ella: suponiéndola evidente, de valor metafísico, no se preocupan de comprobarla prácticamente. Pero al formular el fundamento de su hipótesis, la escuela clásica ha incurrido en una lamentable confusión. La unidad de la naturaleza humana no se encuentra en el criterio moral, sino en la racionalidad de nuestro ser. He aquí el único verdadero punto que enlaza a todos los hombres, a través de la grandísima diversidad de constituciones fisicas. de sensaciones y de sentimientos, de desarrollo intelectual, de criterio moral, de fuerza voluntaria, diversidades todas, separadas aún más, por la labor incesante del progreso, de la civilización.

5 Hasta hace poco hubieta parecido un abaurdo lógico el unir a la idea de metafísica la de tras. cendental, cuando no se podía concebir una metafisica que no tuvista este carícter: pero habiéndose formado en estos últimos tiempos una metafísics inmanente y experimental, de la que me parece set el más legitimo representante el ilustre filòsofo Mr. Alfredo Foulliée, a hace ya necesario dar a aquella ese significado para distinguirla de la nuevs direceión científica. 
¿Cómo podemos decir por un momento que todos los hombres tienen las mismas ideas morales contra el testimonio irrecusable de la Historia? Son, acaso, iguales los principios del bien y del mal reconocidos por los Asirios, por los Griegos, por los Romanos, a los admitidos en la Edad Media, en los siglos XVI y XVI ? Pero ¿para qué irnos a tiempos remotos? En las actuales sociedades es, no idéntico, sino semejante siquiera, el sentido moral del orgulloso Europeo al del resignado fatalista indio, al del feroz salvaje africano? Aun más, ¿en las naciones de la culta Europa, piensa del mismo modo sobre las ideas de lo justo y de lo injusto, el orotodoxo católico, el filósofo y el jurisconsulto espiritualista, que el impla. cable ateo, el obcecado materialista, el socialista intrasigente? Por último, debido a las investigaciones de una ciencia muy reciente y ya muy fecunda, la Antropologia Criminal, se ha venido a comprobar plenamente, que aquello que suponfamos nosotros lo más intimo e imposible de sofocar, el fallo inexorable de la conciencia, los remordimientos, no existen en lo menor, cabalmente, en muchos de los autores de los crimenes más horrorosos.

Si los preceptos de la moral y de la justicia son impresos por Dios en la conciencia del hombre, ¿cómo es, que la Eterna Verdad y Armonía puede haber enseñado principios, que no sólo varían de siglo en siglo, sino de pueblo, de individuo a individuo? Si creemos, Señores, en un Dios, no lo convirtamos en un monstruoso ser miserable causante y justificador de todas las maldades y aberraciones de los hombres!

Los preceptos de la conciencia humana no son sino el resultado de los sentimientos, ideas, creencias de las generaciones que nos han precedido, trahsformadas lentamente $\mathbf{y}$ amoldadas a la constitución especial de cada individuo $\mathrm{y}$ al medio físico $\mathrm{y}$ social en que éste se desarrolla. La persistencia y generalidad de muchas de sus prescripciones se explica fácilmente: Las leyes que rigen el mundo moral y social, a semejanza de las leyes biológicas, están sujetas a mayor o menor duración y autoridad, según sean más o menos importantes los hechos a que se refieren. De modo que cuando una institución jurídica representa una condición imperiosa para la existencia y desenvolvimiento de nuestra naturaleza, puede ya desafiar orgullosa por largo tiempo el terrible y destructor embate de los siglos.

Presentaré un caso práctico de la mayor importancia que comprobará plenamente mi aserto:

La propiedsd, según se halla reconocido en todas las legislaciones, 
de acuerdo con los dictados de la conciencia. es una institución que satisface una exigente necesidad para la existencia y desenvolvimiento de la sociedad actual. Habiēndose ella identificado tanto con nuestro modo de ser individual y con la organización de los pueblos cultos, podemos preveer igualmente que tendrá vida prolongada. Pero contentos con reconocer su importancia y trascendencia positiva y filosófica también, han procurado los filósofos y jurísconsultos elevarla a un dogma de Derecho Natural, de justicia absoluta y eterna. $\mathrm{Y}$ al querer justificar esta institución en sí misma, olvidándose de su valor real y práctico, han incurrido en error, pues despreciando las únicas armas con que podian defenderla con seguro resultado, entregan el cuerpo completamente descubierto a los terribles ataques de las doctrinas disociadoras contemporáneas, que desencadenadas se precipitan violentamente por abierta brecha, que en vano procuran los metafísicos, con sus estériles dogmatismos, cerrar. En efecto, Señores, si se nos quiere llevar a los principios, el socialismo cientifico, no el de Proudhon sino, por ejemplo, el de Laveleye es más bueno y más justo y es más conforme con la moral y con la doctrina cristiana ${ }^{6}$, que el derecho de propiedad tal cual se halla reconocido actualmente.

¿Podemos decir, por un momento, que es natural y equitativo, que desenfrenado derroche un miserable en sus vicios los millones que, sin ningún trabajo heredó de su padre, a quien aborrecia, y cuya muerte esperaba con ansia. o que adquirió de un golpe en aquellos garitos legales que se llaman la Bolsa, mientras que otro hombre que siente bullir en su frente el hervidero de genio, y que oye en su corazón los generosos latidos de la virtud y del trabajo, tiene que mendigar, hincado en el suelo, a aquel aborto de perversidad, un mendrugo de pan, que lo quiere, no para fortalecer su organismo atrofiado, sino para dejarlo devorar por las bocas secas y afiebradas de sus hijos escuálidos, ateridos por el frío y el hambre!

Me serfa fácil continuar presentando ejemplos que robustecieran mi argumentación; pero como de este modo me apartaría demasiado del objeto de mi trabajo renuncio a ello, encerrando en pocas palabras mi pensamiento ya que se encuentra contenido en todo lo que he expuesto.

6 Antiguo y Nuevo Testamento, San Ambrosio, San Clemente, San Juan Crisóstamo, Boasnet, Mgr, Ketteler, Obispo de Mayencer, Cardenal Manine, Obispo Derby . Francisce Huet-nombres y citas de la obra "Le socialisme contemporain" por E, de Laveleye, 4 a. Edición aumentada 1888 . 
El Derecho Natural, como expresión de una justicia absoluta y abstracta. conocida por el hombre, por el esfuerzo de su razón o por la revelación divina. es un concepto quimérico. Esto no importa. sin embargo. la negación de una filosofía del Derecho que dé unidad y fuerza a esta ciencia social. No. ella tiene que existir. pero tomando un aspecto y una tendencia diversa. Ella debe comprender el estudio de los principios fundamentales del Derecho, basados en la experiencia universal, que han sido admítidos por los pueblos civilizados por corresponder a la satisfacción de las necesidades positivas y de las verdaderas aspiraciones de la sociedad. Tales principios no tienen nada de metafísicos, no representan sino las condiciones de existencia de la vida social, no son sino las consecuencias necesarias que se derivan de la naturaleza misma de las cosas. Se les puede calificar de inmutables e imperativos, pero no tomando estas palabras, como dice Ribot, refiriéndose a la moral "en el sentido vago, trascendente, insecuestrable que se les da por lo comûn. sino en un sentido preciso. positivo, incontestable, porque ellos significan que su estabilidad es la de la naturaleza y su necesidad la de lógica". ?

No ignoro, Senores, que el afán de la ciencia moderna por impedir que Dios continúe siendo un manoseado expediente mecánico que solucione todas las dificultades; por separar el Derecho Natural de la metafisica teológica de las ideas absolutas; porque se reconozca en las ciencias sociales el gran principio científico de la relatividad de nuestros conocimientos, ha sido y es aún hoy mismo blanco de los más duros ataques. Sin embargo este principio es, para mi modo de ver. la única base racional del Derecho: Al limitar nuestro pensamiento limita también nuestra actividad en presencia de los otros hombres, y nos impone restricciones cuya regla es la justicia derivada de la naturaleza misma de nuestras relaciones. "La condición racional que necesita la justicia, dice el célebre escritor contemporáneo, el Sr. Alfredo Fouillée, es una restricción de la libertad individual que pueda llegar a ser recíproca e igual para todos. Para fundar científicamente el derecho como tal, es decir como regla comùn y limitación mutua de las libertades, es preciso, pues, un principio coactivo "Abstente, Absteneos". Ved aquí la fórmula propia del Derecho estricto, que es como tal una disciplina, una idea reguladora, y que envuelve también el Sustine de los Estoicos. De este modo la limitación de nuestra libertad práctica por la voluntad de otro, es la expresión legitima, la figura exterior de nuestra limitación científica. No obres en frente de los otros hombres como si tu supieras el fondo de las cosas y el fondo de los hombres, como si tu 
supieras que el fondo de todo es tu placer, tu interés, tu egoismo. "No te erijas en absoluto, es decir, en Dios. Ser que no posees de ningún modo la ciencia absoluta, no practiques el absolutismo con tus semejantes. no dogmatices ni en pensamientos ni en actos. La violación del Derecho ideal en nombre de la fuerza y del interés material o espiritual es el dognatismo en acción, sea materialista, panteista o teológico. Abstenerme de violar la voluntad de otro en tanto que ella no viola la mia, es la actitud que conviene a aquél que no pretende resolver la $\mathrm{X}$, ni en pura materia, ni en sustancia única y necesaria, ni en voluntad absoluta y trascendente, a aquél que no quiere un dogmatismo materialista, ni panteista, ni espiritualista, a aquel que rehusa, en general, dogmatizar, y se abstiene de ello" ... "En otros términos, dice el mismo filósofo, puesto que nuestros pensamientos conscientes son igualmente limitados, en cuanto que ellos no pueden alcanzar el último fondo hipotético de ser o del bien, o si no hay este fondo, la infinidad de la serie fenomenal, expresamos este límite interior limitando nuestras libertades por la igual libertad del otro, expresamos la común limitación de nuestras conciencias individuales, de nuestra ciencia, por la limitación recíproca de nuestras voluntades. Ved aquí el derecho y la justicia, ved el solo liberalismo verdadero, por el cual se evita a la vez el dogmatismo metafísico y el dogmatismo moral" 8

El método científico que humilde, pero noblemente, reconociendo la verdadera condición de nuestra inteligencia, pone como divisa en todas sus investigaciones, este principio de la relatividad de nuestros conocimientos, y que renunciando, por lo tanto, a establecer leyes absolutas sobre las cosas en sf, se consagra exclusivamente al estudio de las relaciones del mundo finito, condicionado, deducidas de la observación atenta de los fenómenos de la realidad, se conoce con el nombre de método positivo o experimental. Considerado así este método, sin querer significar con él un emprisimo vulgar, ni hacerlo instrumento de una determinada secta cientifica, representa la única dirección legítima aplicable a todas las ciencias.

Aunque en el siglo XIX es cuando el método experimental ha recibido cumplida aplicación, no se puede, por esto, negar, que él haya sido empleado con muy feliz éxito, por algunas ciencias, en épocas pasadas. Asf, debido a este fiel e infatigable guía, convirtieron los genios de Copernico, Kepler y Laplace la empírica, grosera astrología dogmática en la ciencia astronómica. El gran Galileo, el ilustre discípulo de Copérnico. 
generalizó el método de su maestro a todas las ciencias naturales, especialmente a la fisica.

Siguiendo la misma dirección, Lavoisier, aquel sublime mártir, cuya colosal inteligencia no pudieron soportar los hombres de la Revolución Francesa, transformó la alquimia en química.

A fines del siglo XVIII y principios del presente, luchaba igualmente la medicina por adquirir unidad y fijeza. El principio de la combustión de Lavoisier, los descubrimientos en anatomía general de Bichat, los estudios fisio-químicos de Laplace, las localizaciones de Flourens no eran sino grandiosos elementos dispersos que no bastaban para dar fundamento estable a la ciencia médica. Pero aparece Claudio Bernard, precedido por Broussais, Magendie y aun por el mismo ilustre octogenario que ahora le ha sucedido en la Academia Francesa, el venerable Brown Sequart, proclamando el método experimental; a su llamada, como a la voz de un conjuro mágico, vienen a él todas las observaciones y descubrimientos de sus antecesores, para encadenarse y prestarse reciproco apoyo, formando un seguro y armónico cuerpo científico. Valiéndose de su método, hizo el gran Bernard asombrosos descubrimientos, especialmente en la fisiología. como la acción de las glándulas digestivas, los nervios vaso-motores, la teorfa del calor animal. Abierto por él el camino, le han seguido los médicos con entusiasmo, y merced a esta nueva dirección, la medicina actual adelante rápidamente explorando terrenos que antes le habian sido del todo desconocidos. Era la medicina de las diversas ramas de la ciencia biológica la que hasta entonces no se había asociado bajo la bandera experimental; unida ella a sus companeras avanzan hoy, orgullosas, todas juntas por el ancho y firme sendero de la observación y de la experiencia.

Después de terribles oposiciones, y escuchándose aún los anatemas, que, con débil y lastimada voz, lanzan todavia los filósofos soñadores, los poetas de la vieja y ya estéril metafísica; osténtase también espléndida, con la hermosura de la fuerza y de la fecundidad la psicología experimental contemporánea. Qué futil y que pobre se presenta, comparándola con esta escuela, la antigua, pero aún subsistente psicologia dogmática, con su teorfa de las facultades, en la que aparece el espiritu, según la bella y exacta metáfora de Bailey; "como si fuera un campo en el que la percepción, la memoria, la imaginación, la razón. la voluntad. la con- 
ciencia y las pasiones ejecutarán sus maniobras. como otras tantas potencias aliadas entre si unas veces y en abierta hostilidad otras" ".

La nueva escuela ha demostrado que aquellas entidades que venian a convertir el espiritu en una verdadera república con diversos e independientes ministros y empleados subalternos. no son sino meras concepciones abstractas, cuya subsistencia sólo se puede tolerar. con tal que se les considere desempeñando el mismo papel que aquellos nombres de las ciencias naturales, que como calor. magnetismo, luz, sirven para reunir hechos semejantes y designar causas desconocidas de fenómenos cono$\operatorname{cidos}^{10}$. Imitando el ejemplo de las ciencias naturales, la psicologia experimental se consagra de una manera exclusiva a la investigación de los fenómenos psicológicos, para llegar así por medio de la doble observación interna y externa, subjetiva y objetiva, al conocimiento de las leyes $y$ de las causas eficientes que rigen a éstos, abandonando el orgulloso e irrealizable empeño de querer descubrir lo que es la esencia del alma humana. La vaciedad de la vieja psicologia y la necesidad e importancia de la nueva escuela se comprueba plenamente al ver, que mientras aquélla, en su parte metafísica, no ha adelantado en lo menor desde Aristóteles hasta el día. ésta en pocos años ha producido numerosísimas obras llenas de datos y leyes desconocidas, convirtiéndose, según la bosquejan los directores de las nuevas tendencias, en una ciencia de incalculable atractivo y valor, no exclusivamente para el filosofo consagrado a los estudios especulativos, sino en general para el común de la gente, que puede aprender en ella muy fecundos conocimientos para su conducta en la vida práctica: Por la psicología experimental descubrimos la íntima relación del tejido nervioso con la vida psiquica, las leyes mecánicas invariables que rigen la intensidad y duración de las sensaciones, desde la simple y débil sensibilidad orgánica hasta la más viva del placer y del dolor; la acción del movimiento molecular afarente $y$ eferente, del simple acto reflejo, la actividad inconsciente del alma, que conducida por la corriente nerviosa, se nos presenta cual tenebroso laboratorio en el que se forjan los elementos rudimentarios, que han de servir luego de condición imprescindible para la existencia y desenvolvimiento del espíritu humano, asistinos a la admirable embriología de la inteligencia, que, partiendo do la percepción de una sucesión y de una simultaneidad, llega en virtud de la universal icy psicológica, la asociación de ideas, sostenida por la memoria, a la creación de todos los órganos. funciones y nociones del entendimiento, condicionado por la herencia y 
la educación: presenciamos el origen y la evolución del poder voluntario: para observar. luego. después de este vastísimo campo descriptivo. en conjunto. al hombre adulto en su estado normal y patológico. en comparación con los seres inferiores, con el niño, con el salvaje y el criminal. La nueva escuela. empleando terrible e incesante martilleo, ha hecho pedazos la tradicional estatua del hombre idea. con sus facultades innatas. existiendo cada una por sí, con su cerebro, órgano independiente, perfecto $y$ único del espiritu, con su voluntad caprichosamente absoluta, para reemplazarlo por el hombre vivo, por el verdadero ser racional, cuya inteligencia, a manera de un Kaledeiscopio, aparece iluminada ya por los resplandores sublimes del genio, ya por la fosforescencia morbosa del alucinado, ya por la tétrica luz que lanza el homicida y el incendiario.

Inútil es seguir citando otras ciencias que como la Economia Politica, la Historia y en general la Sociologia, han abrazado, con decidido empeño y halagúeños resultados, el método positivo. Basta creo, lo expuesto, para hacer ver la generalidad de su aplicación en nuestro siglo y la urgencia de que las otras ramas del saber humano que se manifiestan aún reacias, lo adopten inmediatamente, bajo,pena de quedarse rezagadas y olvidadas en el escabroso y elevado camino ascendente por el que suben. orgullosas, las demás sostenidas e impulsadas por el mismo suelo que pisan. En aquella condición se encuentra la ciencia del Derecho, muy especialmente la Penal, por la indole y trascendencia de los estudios que ésta comprende.

Ninguna de las ciencias jurídicas presenta para mi, mayor importancia, que la ciencia del Derecho Penal, asi como de todas las instituciones sociales, ninguna es, para mi opinión, más sagrada que el Poder Judicial castigando al hombre.

La razón es sencilla: El Derecho Civil, el Constitucional, el Administrativo, el Internacional, todos ellos nos manifiestan lo que es lícito hacer al individuo, al Estado, a las Naciones en el concierto con sus semejantes. siendo al mismo tiempo un medio de desarrollar nuestra actividad, ilustrando la inteligencia en los derechos que podemos reclamar y en las obligaciones que debemos cumplir. Pero el Derecho Penal y su aplicación práctica son estudios esencialmente distintos: por ellos se coacta la libertad del ser racional empleando la violencia, por ellos se castiga al hombre invocando a la Sociedad. Atribución solemne en la que se encierran los 
problemas más sagrados referentes a nuestra naturaleza y a nuestro destino. ¿Es el hombre libre y responsable de sus actos? $\mathrm{Y}$ si lo es ¿hasta qué punto influyen en êl, su organismo físico, el medio social en que vive? ¿Se puede sacrificar la voluntad del individuo a las conveniencias sociales? ¿Tiene la sociedad derecho de castigar? ¿Qué castigos puede ella usar lícitamente? He aqui, en breves palabras, precisadas cuesiiones de carácter esencialmente diverso a las que desarrollan las otras ramas de la jurisprudencia, cuestiones gravisimas cuya solución interesa vivamente al hombre $y$ a la sociedad.

Inútil es fatigarse en ir a buscar en la oscuridad de los tiempos primitivos el primer pueblo que comenzó a aplicar el castigo contra sus asociados. Antes que los hombres se hubieran unido, formando grandes colectividades con los nombres de tribu, ciudad, provincia o nación, aparece la horda salvaje en la que el jefe de ella, superior a sus compañeros por su fuerza física y por su ferocidad, sacia sus apetitos bestiales en la carne sanguinolenta del desgraciado que osó contrariar su más insignificante capricho. Aquí es donde se encuentra el primer eslabón de aquella horrible e interminable cadena, formada por articulaciones y miembros humanos, que destilando sangre y lanzando de su interior quejidos espantosos, presenta la sombría y vergonzosa historia de los sufrimientos y martirios de los hombres sacrificados por sus semejantes.

Vosotros, Señores, sabéis mucho mejor que yo, antes que apareciera el heroico puebio romano, dominando al mundo, la superioridad y la perfidia eran la norma que regía las relaciones sociales. Sólo a la patria de Justiniano se deben aquellas sublimes intuiciones, aquellas inmortales leyes, que después de tantos siglos de promulgadas, tiempo en el que de grandes imperios, únicamente se conserva vago recuerdo, ellas, llenas de verdad y grandeza, dan vida $y$ aliento al Derecho moderno. Pues bien, aquel pueblo tan investigador y tan práctico, no comprendió la ciencia Penal. Pacheco explica este atraso, atribuyéndolo al socialismo o comunismo que dominaba en las sociedades antiguas. Según el eminente escritor, para que prospere y fructifique el Derecho Penal es necesario que se afirme fuertemente, y sea reconocido el valor de la individualidad humana; y como ella era negada en el Imperio Romano, donde la personalidad de los ciudadanos desaparecía ante el despótico capricho del César, aquella ciencia no pudo nacer alli. Por razón inversa tampoco la encontramos en la Edad Media: Los pueblos bárbaros llevaron a cabo una obra terrible, pero necesaria y benéfica; destruir de rafz la sociedad antigua, corrompida y envilecida por el servilismo y por los vicios, fue la tarea inconsciente efectuada por los feroces invasores; para ello obedecieron a dos principios: su indi- 
vidualidad como única ley. la fuerza física como único medio. No reconociendo ningún poder social, la razón estaba siempre por el más fuerte. Con semejantes ideas era imposible no que tomara cuerpo. sino que germinara siquiera, la idea de una justicia igualmente obligatoria para el débil y para el poderoso.

El Derecho Penal requiere, para su existencia y desarrollo, perfecta equivalencia y reconocimiento de dos entidades que merecen el mismo respeto y consideración: el Individuo y la Sociedad.' Al sacrificarse a alguno de ellos se falta a la justicia y se entorpece la marcha progresiva de los pueblos. Siendo esto cierto, se comprende también fảcilmente por qué la ciencia Penal no pudo tampoco prosperar en las cortes de un Enrique VIII o de una Isabel de Inglaterra, de un Felipe II o de un Luis XIV.

El génesis del Derecho Penal, como estudio cientifico y filosófico, se encuentra en una obra admirable escrita en el siglo anterior por un espíritu muy levantado, por un corazón muy genroso, lleno de amor hacia sus semejantes. Beccaria, el joven profesor de la Universidad de Milán, al trazar, con la fiebre del sentimiento $y$ de ta indignación, las inspiradas e inmortales páginas "De los delitos y de las penás", se encaró, a nombre de la humanidad doliente, ante los reyes y los poderosos, ante la sociedad y sus instituciones, para exigirles los títulos con que ejercian el derecho de castigar. Aquella audaz protesta no se perdió en el vacio: Satifaciendo el libro una apremiante necesidad, largo tiempo sentida, y escrito al alcance de todas las inteligencias, adquiere en un momento fama universal: sólo en Italia se hacen de él 32 ediciones, se le traduce a 22 idiomas, es materia de grandes controversias en casi todas las Universidades de Europa, y el inspira los profundos trabajos de Romagnosi, Filangieri, Bentham, Pastoret y Fuerbach. Esa obra sublime, transformada por el pueblo en gritos de odio implacable, de venganza feroz, repercute lúgubremente en las sangrientas escenas de la revolución francesa, y da una lección elocuentísima, pero terrible, al hacer rodar por el suelo, victimas del mismo suplicio, la cabeza de Luis XVI y la de Robespierre.

El objeto que Beccaria se propuso al escribir su inmortal obra, bien categóricamente lo expresa en el prefacio de ella: "Algunos restos de la legislación de un antiguo pueblo conquistador, compilados por orden de un principe que reinaba hace doce siglos en Constantinopla, mezclados en seguida con los usos de los Lombardos, y amortajados en un färrago voluminoso de comentarios oscuros, forman ese viejo montón de opiniones que una gran parte de la Europa ha honrado con el nombre de leyes: y hoy mismo el prejuicio de la rutina, tan funesto como general. hace 
que una opinión de Carpsovius, un viejo uso indicado por Clarus. un suplicio imaginado con bàrbara complacencia por Farinacius. son las regias que siguen friamente esos hombres, que debian temblar cusndo deciden de la vida y de la fortuna de sus conciudadanos. Es a este código informe. que no es sino una monstruosa producción de los siglos los más bárbaros, que yo he querido examinat en esta obra. $"$

El ilustre jurisconsulto francés, Faustỏn Hélié, comentador del libro de Beccaria, completa este cuadro, entre otris, con las siguientes palabras. "En lo que concierne al procedimiento, la audiencia de los testigos por vía de investigación. las comprobaciones y confrontaciones a puertas cerradas, las sentencias sobre el proceso verbal de esta instrucción escrita: tales eran las solas garantias de la justicia. De ahi la incertidumbre que parecía pesar sobre todos los procedimientos criminales, los esfuerzos de los jueces por obtener la confesión de los acusados, las sutilezas de los interrogatorios y las torturas del tormento. Las leyes penales estaban informadas por el mismo espiritu; los castigos eran atroces, no se contentaban con condenar a muerte a la mayoria de los criminales, se aumentaba esta pena con horribles sufrimientos: y el juez. cuando se trataba de atenuarlas se hallaba encadenado por las máximas de la jurisprudencia o por los textos de las ordenanzas, gozando siempre en cambio de un poder ilimitado para extenderlas. Esta legislación, llena de asechanzas y trabas. y armada de severidades inauditas, no sospechaba el derecho de una defensa, la equidad de una proporción entre los delitos y las penas. Ella miraba en el acusado a un enemigo: lo secuestraba en lugar de facilitar su justificacion. Ella lo hería antes que fuera condenado. Su único principio era la vinđícta pública, su fin único, la intimidación" 12 .

A esta legislación en conjunto, a este procedimiento general, no en una determinada forma, delito o castigo, sino al sistema entero es contra el que Beccaria dirige su irresistible elocuencia. "El no busca absolutamente, si entre tantas instituciones, hay algunas que deben sobrevivir. No las examina, no quiere mejorarlas; él quiere renovarlas".

Con la modestia del hombre de verdadero mérito reconoce que no debe a si mismo las ideas de su obra. "Yo, dice al abate Morollet, debo todo a los libros franceses. Son ellos los que han despertado en mi alma

11 Beccaria: Des đálits et des peines, traducción francesa. Introducción, comentarios y notas de Faustin Hébé 2a. Edic franc. 1870 .

12 Fauston Hélié. - Introducción as traité des Délit et des peines de Becearia Obr. cit. 
los sentimientos de humanidad. ahogados por ocho años de educación fanática". D'Alembert. Diderot. Buffon. Hume. muy especialmente Rousseau. Montesquieu y Helvetius son sus maestros. Posesionado de las ideas de los escritores revolucionarios, ideas todas que él aprovecha exclusivamente para su sistema criminal, opone luego al feroz empirismo fanático de aquellos tiempos, al sombrío y sanguinario sistema espiatorio, la teoria humanitaria de la proporción de los delitos y las penas, de la disminución de éstas, de la supresión de los tormentos, de la pena de muerte, de los procedimientos secretos; organización de una justicia que respete los derechos del individuo, que establezca las garantías necesarias para su recta y equitativa, no arbitraria e inhumana, aplicación.

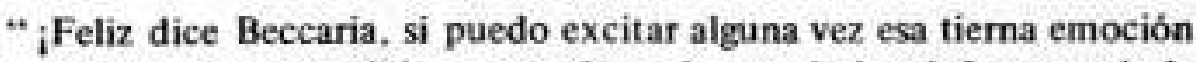
por la cual las almas sensibles responden a la voz, de los defensores de la Humanidad”. „Descansa en paz. noble alma. ante tu nombre, profundamente emocionada, se inclina la Humanidad entera, respetuosa y agradecida!

Pero ahora, dejando a un lado la grandísima importancia del libro de Beccaria, considerándolo, desapasionada, friamente bajo su aspecto filosófico, diré que más que una profunda obra científica es una obra de combate, de sensación, lanzada en un momento histórico oportuno. Sin embargo, ella obedece a un método. "Su método, consiste dice su ilustre comentador, en buscar a priori, cuáles deben ser los principios de una legislación racional, cuál es el verdadero fundamento del Derecho Penal, cuáles son las leyes de la acción represiva, cuáles hechos puede ésta comprender, cuál el carácter y la medida de las penas". Por otra parte en muchos importantes pasajes de su libro. Beccaria se afilia explícitamente al método experimental. El fin de las leyes debe ser "todo el bienestar posible para el mayor número" (principio utilitario de las mayorias) ${ }^{13}$. "La justicia humana o si se quiere, la justicia politica, no siendo sino una relación convenida entre una acción y el estado variable de la sociedad, puede cambiar también a medida que esta acción sea ventajosa o necesaria al estado social. No es posible determinar la naturaleza de esta justicia, sino examinando con detención las relaciones complicadas de las inconstantes combinaciones que gobiernan a los hombres" 14. "Que se recorra con una mirada filosófica las leyes y la historia de las Naciones, se verá casi siempre los nombres de vicio y de virtud, de buen y de mal ciuda.

13 Obra y edición citadas püg. 11.

14 Obra y edición citada pág. 5. 
dano, cambiar de valor según las circunstancias. A menudo se verá las pasiones de un siglo servir de base a la moral de los siglos siguientes. y formar toda ia politica de aquéllos que presiden a las leyes. Es por el debilitamiento de las pasiones fuertes, que han nacido entre los hombres, las nociones-oscuras del honor $y$ de la virtud, $y$ esta oscuridad subsistirá siempre, porque las ideas cambian con el ticmpo, que deja sobrevivir los nombres a las cosas, y ellas varian según los lugares y los climas: la moral está sometida, como los imperios, a límites geogríjicos, ${ }^{15}$

A mi modo de ver, Beccaria, viviendo en un medio social, fanáticamente intransigente, no ha podido o mejor dicho no ha querido desarrollar todos los gémenes que encerraba su pensamiento. De aqui que al leer su obra, hiera desagradablemente la vista, encontrar una protesta viril, llena de fuerza y de sentimiento, precedida o continuada por humildes reservas y excepciones, una reforma audaz al lado de una confesión seminarista. En una palabra, Beccaria ha tenido el suficiente valor $y$ sinceridad para atacar los abusos e injusticias contra los que se revelaba su conciencia moral, esencialmente humanitaria; pero se ha acorbardado y detenido ante su pensamiento filosófico, timidez que redunda en detrimento de la importancia cientifica de su libro.

Aquellas palpables inconsecuencias y contradicciones dan al tratado "De los delitos y de las penas" tal elasticidad, que según el prisma bajo el cual se le mire, él puede servir de origen y fundamento a las dos opuestas e irreconciliables escuelas penales, que actualmente, por la violencia del combate, atraen la atención del mundo científico: la escuela Clásica y la Positiva italiana. Pero ya por ser nota predominante en el libro, la investigación subjetiva a priori, o ya por haberse apoderado de él los jurisconsultos clásicos, lo cierto es que la obra de Beccaria representa en la ciencia penal, la progenitura de la escuela Clásica.

Siguiendo esta dirección, nadie ignora cuántos sistemas penales se han presentado desde que apareció el libro del joven jurisconsulto milanés; pero todos ellos, tanto la teoría de la justicia absoluta de Stahl, la de la intimidación de Klein, la de la prevención en los diversos aspectos bajo la cual la consideran Fuerbach, Bauer, Grolman como de la defensa del Estado de Martin, la de la reparación de Weleker y la nueva y más pres- 
tigiosa teoría correccional de Roder ${ }^{16}$. están unidas bajo un lazo común que permite afiliarlas bajo el nombre genérico de la escuela clásica Penal. De esta manera se facilita muchísimo el trabajo de refutación que se quiere emprender sobre ellos, porque reposando principalmente sus opuestos errores de consecuencias y aplicaciones en los principios universlaes que todos reconocen, al hacer ver en general la ineficacia de éstos, combatiéndolos en su propia base, se desploman luego los sistemas que sobre tal fundamento se habian edificado.

El concepto filosófico del que la teoría clásica penal deduce sus diversos sistemas es, como ya he dicho de la escuela considerada en su generalidad, el de la existencia de un Derecho eterno y absoluto, por medio del cual es posible estudiar a priori el delito juridico abstracto. Establecido el principio, y empleando luego el método deductivo, cada uno saca de el opuestas consecuencias, contradictorias leyes universales, que en su falsa generalización comprenden todos los delitos, todas las penas, todos los delincuentes, por más diversas que sean las naturalezas especiales de cada uno de estos, y el medio físico, el tiempo histórico, el estado de cultura de la sociedad en que ellos se desarrollan.

Conociendo la capital importancia que representa aquella idea abstracta de la justicia en toda la ciencia del Derecho, muy especialmente en la Penal, me he ocupado de ella en la primera parte de mi trabajo. Basándome en to expuesto sostengo, que la escuela Clásica criminal desconoce la ley psicológica de la relatividad de nuestros conocimientos y cierra los ojos a la Historia que enseña que todo cambia y evoluciona, al dar como fundamento inamovible de su doctrina, conceptos absolutos del derecho y del delito. Querer probar que sus teorías son rigurosa deducción y consecuencia de la justicia intrínseca, de una absoluta ley moral rigiendo las relaciones humanas, es abandonar la tierra solida y segura de la realidad para entrar en la nebulosa región de la metafísica, perdiendo ahí en estériles sutilezas escolásticas, las fuerzas que son necesarias todas, para combatir sin tregua contra aquellos actos que transtornan el orden social.

La felicísima comparación hecha con la ciencia médica por uno de los más notables propagandistas de las nuevas ideas, manifiesta, con la mayor expresión y claridad, el falso aspecto bajo el cual considera la

16 V. Roder: Las doctrinas fundamentales reinantes sobre el debto y la pena; trad. de F. Giner, 1876. 
escuela Clásica al Derecho Penal. y el nuevo camino que éste debe seguir. $\mathrm{La}$ medicina antigua era una ciencia esencialmente nosológica, ella sólo se dedicaba al estudio y descubrimiento de la enfermedad con prescindencia del enfermo. En presencia de éste. el médico consagraba toda su atención a encontrar el morbo. la enfermedad en abstracto. sin preocuparse en lo menor del temperamento especial del individuo, de su organismo, de sus antecedentes hereditarios o personales, de las causas internas o externas de las que podria provenir la dolencia. Se consideraba la enfermedad invariable cualquiera que fuese la naturaleza y condiciones del paciente. "De la misma manera el Derecho Criminal ha consistido en el estudio de los delitos, como entes abstractos: el criminalista ha estudiado el hurto. el homicidio, la estafa, en si, como entes juridicos, como abstracciones, y con el auxilio de la lógica abstracta y de los propios sentimientos del hombre honrado, creyendo, cuando no lo son, iguales sus propios sentimientos a los del delincuente, ha establecido que el remedio de los delitos es la pena, y con un cálculo que muchos e ilustres criminales declaran imposible cientificamente, ha establecido para cada delito una pena como en las antiguas formulas médicas a cada enfermedad se señalaba un específico. El hombre que comete el delito, para el criminalista clásico está en un lugar muy secundario, como antes el enfermo para los médicos, y no es para él como para éstos sino el sujeto de aplicación de las fórmulas teóricas. Evidentemente el criminalista, como el médico de las antiguas escuelas, han debido ocuparse del delincuente como del enfermo, por algunas condiciones personales demasiado pronunciadas, según las cuales, se dice. se modifica la imputabilidad moral del hombre. Pero las demás condiciones orgánicas o psíquicas del delincuente que no están enumeradas en las contadas que aprecian (menor de edad, sueño, locura, embriaguez. impulso de afectos), tales como la influencia hereditaria, las condiciones del ambiente físico y social, que constituyen los precedentes inseparables de la persona del delincuente, y por consiguiente de sus acciones, el criminalista prescindía en absoluto: curaba los delitos y no los delincuentes. precisamente como los médicos de otro tiempo" 17 .

Colocados los criminalistas clásicos en la elevadísima cima de la justicia absoluta, del delito abstracto $y$ del delincuente ideal, con el vértigo de la altura y de la distancia, no ven que se levanta de la tierra el criminal más terrible que nunca, mediante los elementos que le presta el refinamiento de la civilización, ni oyen las horrorosas imprecaciones de odio y de amenazas con que ahoga los ayes lastimeros de sus victimas. 
Impasibles aquéllos, no observan, que sus formulas a priori y sus medidas prácticas deducidas de éstas, son impotentes para contener el desborde de la criminalidad; no se fijan en que la Estadistica comprueba plenamente que los delitos aumentan de un modo aterrador, y que entre ellos los más espantosos son los más frecuentes.

Para que la ciencia Penal produzca los frutos que los adelantos de nuestra civilización tienen derecho de exigirle, urge imperiosamente que ella tome una via distinta. Es preciso que sus conceptos y leyes no sean puras abstracciones e idealidades de la razón, guiada por la conciencia subjetiva apasionada y falible, sino nociones y principios positivos, en correspondencia con profundo análisis y conocimiento de los hechos y de las necesidades actuales de la sociedad; es indispensable que estudie como elemento principal al delincuente, no fantástico sino verdadero, que se analice su constitución física y moral, que se reconozca y establezca la influencia que en él ejerce la naturaleza y las ideas y sentimientos del medio social que le rodea. Sólo de esta manera conseguirá que sus leyes, en vez de ser meras utopias dogmáticas, se conviertan en fecundos y permanentes remedios de los males sociales.

La ineludible e inmediata necesidad de que el Derecho Penal cambie de método, procuraré que resalte al hacer ver el error e ineficacia de muchos de los conceptos, que, de aquella idea abstracta del derecho y del delito, deduce la escuela tradicional.

Lo único que siento, Señores, es que los limites naturales de mi tesis no me permiten tratar de esta materia, con toda la extensión que demanda la trascendencia, interés y dificultad del asunto.

Los conceptos más equivocados de que adolece la antigua escuela se encuentran al ocuparse y resolver dogmáticamente el problema de la responsabilidad criminal. Consecuentes con la teoria psicológica de las facultades, de la que ya he hablado antes a la ligera, suponen que cada una de éstas, son entidades completamente independientes, que tienen vida propia y poderío absoluto sobre el organismo. Valiéndome de una metáfora ya vulgar, pero en este caso muy oportuna y exacta imaginan que aquéllas salen al mundo y vienen dotadas con tan varias e irresistibles fuerzas, como las que posefa Minerva, al salir de un golpe, armada de pies y cabeza, de la frente de Júpiter. Estableciendo luego, que de las diversas facultades es la razón la jefe y directora, deducen que el hombre es responsable de sus actos, cuando mediante la propia iniciativa de ésta, sin hallarse coactado por una persona extraña, causa intencionalmente 
un dano a sus semejantes. Al desarrollar este raciocinio se inspiran en dos suposiciones: 1a. la completa libertad de las facultades intelectuales y morales, y más concretamente para mi asunto. de la conciencia moral del hombre, $2 \mathrm{a}$. El poder que tiene éste de dominar siempre sus sentimientos y pasiones por su sana razón, mereciendo por tanto el castigo cuando procede en contra de los dictados de ella. Estas dos cuestiones en la esencia, son la misma; a las dos pues voy a referirme ahora y paso a señalar, según los conocimientos universalmente admitidos hoy por la ciencia, algunas principales de las múltiples influencias que cjercen decidida presión sobre el entendimiento, la facultad moral y la voluntad.

Gran vacío de la filosofia espiritualista es la falta de una seria investigación sobre las relaciones de lo físico con la moral ${ }^{18}$ que ocasiona fatalmente graves prejuicios, llevando muy a menudo a la ciencia Penal. la incertidumbre, cuando no el error, al querer resolver los intrincados y trascendentales problemas que ofrece el estudio científico de la responsabilidad cirminal. Separando las funciones espirituales de orden inferior. que, como las sensaciones y las percepciones de los sentidos, reconocen depender en gran parte del órgano correspondiente material, y exceptuando también aquellas enfermedades aniquiladoras que irresistibles producen fuerte sacudida, suspensión o desconcierto completo, o la ruina total del espíritu, dejando siempre impresa en el individuo indeleble señal que se percibe y se palpa a primer golpe de vista, sin necesitar hallarse iniciado en los secretos de la fisiología y de la patología; fuera de esos casos tan conocidos por su generalidad o por su gravedad, como la acción implacable del organismo físico en el tiempo, especialmente durante la infancia $y$ la senectud; como la locura ( $s i$ al fin llegan a admitir que ella tiene su origen en un desequilibrio del sistema nervioso) o como la embriaguez momentánea; la antigua psicologia, y con ella la escucla Cläsica Penal, cegadas por su método a priori, han desconocido la perpetua, intima y verdadera influencia de la naturaleza general y de las condiciones y estados especiales del cuerpo sobre los sentimientos, ideas y voliciones del alma.

Contra la teoría metafísica de la absoluta independencia del espiritu, la ciencia moderna ha demostrado, con la luz de la evidencia, la verdad que contienen las siguientes palabras del profundo filósofo inglés

18 Aquí hablo de la filosofia espiritualista; esto, pot tamto, no vignifica que deje de reconocer, que ilustres filósofos idealistas como Maine de Biran, han tratado con profundidad esta delicada materia. 
Alejandro Bain. "No hay ejemplo alguno de dos agentes tan estrechamente unidos sin alguna intervención o apropiación mutua, como la inteligencia y el cuerpo" ${ }^{\prime \prime}$ En efecto, si tomamos la prueba más simple y general, la de los temperamentos, la fisiología nos enseña, que mientras quo el hombre sanguíneo es de carácter sentimental y alegre, de imaginación pronta y de fácil memoria; y el nervioso muy irritable y sensible, de pasiones concentradas, de ideas atrevidas; el bilioso se presenta fuertemente excitable y muy reflexivo, y el linfático con escasa sensibilidad y débil inteligencia. "Sì el temperamento nervioso, dice el célebre doctor Berthier, conserva la emocionalidad, el linfático implica la indolencia, el bilioso la ira. Estos estados crean o provocan inclinaciones mórbidas; ved aquí otras tantas causas que pesan sobre nuestras sensaciones, después sobre nuestras ideas, en fin sobre nuestros actos" ${ }^{20}$. La constipación -se ha visto la prueba con Napolcón, Talma y algunos otros grandes hombres, escribe más arriba el mismo ilustre médico alienistaagría el carácter; ciertas personas sujetas a ataques del estómago, habiéndolos éstos debilitado, se vuelven irascibles, la sordera mantiene la cólera y la desconfianza ${ }^{21}$. Las descomposiciones, irregularidades y anomalías del aparato digestivo repercuten también tristemente y con mayor fuerza de las anteriores, en el sistema nervioso, con especialidad en la masa encefálica y en el espíritu del paciente. Los violentos ataques de dispepsia no solo ocasionan en ciertos casos terribles opresiones y fatigas del corazón, dolores agudisimos, desfallecimientos o desarreglos del cerebro, anestesias especiales o generales, dejando muchas veces a su victima en estado de anonadamiento o estupor, sino que, y esto es lo más frecuente. los padecimientos de la digestión, fuera de sus efectos fisiológicos, crean una actividad ficticia, trastornan e irritan sobremanera la sensibilidad y el carácter, y despiertan a veces ferozmente instintos bestiales, ansias sanguinarias y de destrucción insaciables. La dispepsia tenaz deja fatal huella en el temperamento y en el carácter del individuo, volviéndolo taciturno, sombrío, irascible; el dispéptico crónico concluye en hipocondríaco. El concienzudo escritor argentino, Sr. J. M. Ramos Mejía, en su inapreciable biografia del lúgubremente célebre tirano de Paraguay, Francia, se expresa en estos términos: "Si conociérais de lo que es capaz un pedazo de alimento que se digiere mal, y que va trabajosamente abriéndose paso a través del intestino por cuatro o seis largas horas, comprenderéis, cómo sería posible, que una mala digestión alterara el

20 Berthier. Des Névroses menstrerelles 1874.

21 Berthiet id. 
ánimo de aquel melancólico destructor hasta el punto de hacer traer a su hermana para fusilarla" 22 Las noches en que aquel feroz dispéptico. atormentado por su implacable enfermedad. no pudiendo gozar. siquiera por cortos instantes. de la acción reparadora del sueño, procuraba una distracción a su hipocondria homicida. a su locura melancólica, pesan sobre la historia de su patria como una horrible pesadilla. "Cuentan los que le sobrevivieron, dice el citado escritor, que una de sus noches de insomnio costaba más al Paraguay que veinte conspiraciones".

Bajo otro aspecto, y refiriéndose a ciertos hombres, que en tiempos pasados abundaban especialmente en Asia, dice la autorizada palabra de Mausdley: "Todo lo que se sabe sobre ellos corrobora la opinión de que son por la mayor parte falsos, mentirosos, cobardes, envidiosos, ruines. desprovistos de sentimientos sociales y morales, mutilados del espíritu como del cuerpo".

Hay excitantes y venenos, que sin causur trastorno intelectual palpable, originan gran debilitamiento y cambio en el espiritu: El abuso inmoderado del tabaco determina, según notables autores, una impresionabilidad y una irritabilidad exagerada en el carácter. Decaisne y Bertillon han observado, que este vicio dana especialmente a la inteligencia de los jóvenes, y el Dr. Venturi que es un signo evidente de decadencia mental. El Dr. Moreau de Tours, con su brillante pluma, describe los perniciosos efectos intelectuales de la habitual masticación del hachisch indio ${ }^{23}, \mathrm{Y}$ Legrand du Saulle, citando al Dr. Motel, se alarma justamente del inmenso consumo de ajenjo en Paris y Argel ${ }^{24}$. Respecto a los viciosos fumadores de opio. dice el Dr. Cullerre, que su inteligencia y el sentido moral se borran de más en más, concluyendo muchos por pedir al robo la satisfacción de su triste hábito: sobre cuarenta chinos encerrados en las prisiones de Singapour treinta y cinco eran fumadores de opio ${ }^{25}$. Y el mismo escritor, hablando de la morfinomanía, dice. que ella causa con frecuencia un embrutecimiento progresivo, una grande irritabilidad del carácter, la incertidumbre, timidez, hipocondría ... Las facultades morales son más especialmente atacadas: El morfinómano es moroso, irritable, egoista, misántropo. El se humilla hasta los actos más hipócritas, a la astucia, a

22 J. M. Ramos Mejia: Las Neurosis đe los hambres cékebres en la Historia Arpentima, 2a. Parte 1882.

23 Moreau de Tours: Du hachisch et de Ialienation mentak, 1845.

24 Legrand du Saulle: La folic derant les Tribunaux, 1864.

25 Cullerre: Nervosisnie et névroses, 1884. 
la mentira para procurarse su veneno favorito. El espiritu languidece, la memoria se debilita: en muchos casos. sin embargo. nada exterior denota tl hábito enfermo, asi gran número de morfinómanos continúan llenando sus deberes sociales con la corrección habitual ${ }^{26}$.

Se sabe también la gran fuerza, que ciertas sustancias tóxicas y medicamentosas ejercen sobre la emocionabilidad y voluntad de los individuos.

He citado todos estos casos secundarios, para hacer ver hasta qué punto llegan a influir las causas físicas, la condición del organismo, en el elemento espiritual.

Pero no insistiendo en la acción de los temperamentos típicos, que en la realidad se compenetran y confunden, formando grandes variedades, y no deteniéndome tampoco en otros, males, vicios y causas físicas análogas a las que he citado; debo ya fijarme en varias leyes fisiológicas y enfermedades, que influyen profundamente en la responsabilidad del individuo, causas descuidadas por la escuela Clásica y de las que, sin embargo, no pueden prescindir, en justicia, ni la ciencia, ni los códigos Penales.

Los fenómenos biológicos de la pubertad y de las enfermedades especiales de las mujeres ocasionan muchas veces la más fuerte conmoción en el organismo nervioso, modificando bruscamente los sentimientos y los caracteres, y despertando, con desgraciada frecuencia gérmenes morbosos que se hallaban en estado latente, y que ahora, removidos por la fuerte crisis del cuerpo, se agitan terriblemente en el interior, y se lanzan furiosos sobre el cerebro y la inteligencia, para llevar ahí el desconcierto y la desolación, incitando, con imperio irresistible, las más bajas pasiones, depravando y envileciendo el sentido moral, impeliendo finalmente la voluntad para el crimen, cuando no terminan su funesta labor destructora con la demencia o imbecilidad de su victima 27 .

El principio fisiológico más general, antes desconocido y ahora muy estudiado, que condiciona nuestro cuerpo y, también, nuestro espiritu es la Herencia. Esta, en su acepción genérica es la ley biológica por la cual

26 Culactre, 14.

27 Moresu (de Tours) Psychologie morbide, 1859.- Legrand de Saulle: La folie devant les tribanaux, 1864; Medicina Legal trad. del Dr. Jañez y Font, 1890; - Berthier: Desećvroses thens truelles, 1874 - Tradieu: Estudio médico kgal sobre la locura, trad, esp. por D. P. Setefiana, 1883 Brierre de Boismont; De la menstruation - Leard: La femme pendant le periode menstruelle 1890. 
todos los seres dotados de vida tienden a repetirse en sus semejantes (Ribot). La herencia en el mundo viviente es la fuerza centripeta que representa la unidad y la armonía. En virtud de ella. los hijos se asemejan a sus padres tanto física como moralmente. La herencia moral se halla sancionada por la religión Cristiana en el dogma del pecado original y en la maldición de Dios sobre la raza de Caín y sobre el pueblo judio.

El estudio de la herencia es uno de los asuntos de más palpitante interés, cuyos alcances asombrosos discuten con la mayor solicitud los sabios de la Europa. ¡Y tienen razón, Señores! cuando desde las alturas de la filosofía se sigue la evolución de este fecundo principio, y se le observa ejerciendo su acción fatal e inexorablemente en los mundos botánico y zoológico, aunque permitiendo en éste algunas excepciones; y se le mira en el antropológico, clasificando las razas y los pueblos, y transmítiendo a los hijos, no solo la configuración física, la fisonomia, las facultades perceptivas, las enfermedades de los padres, sino también, y a pesar de los innumerables obstáculos que aquí se le oponen, el carácter, la memoria, las aptitudes artísticas, $y$ hasta, $y$ no en raros casos, la inteligencia esclarecida ${ }^{28}$; tenemos que inclinarnos ante la ley de la herencia, y en lugar de negarla con hinchada y hueca fraseología, reconocer su valor $\mathrm{e}$ investigar sus verdaderos efectos.

Bajo su aspecto psicológico, la herencia imprime su sello a las especies y a los individuos. Como ley específica es fatal e ineludible: ella no sólo por la organización física, sino especialmente por cualidades morales. ha podido señalar los rasgos distintivos de las dos grandes razas semitica y aria o indo europea, y de esta última los de los pueblos latinos y germanos.

Fuera del ejemplo de las razas típicas, la prueba experimental más palpable que se puede dar de la generalidad y persistencia de la ley hereditaria psicológica en las masas, se encuentra en aquella palabra que repetimos inconscientemente, y que encierra, sin embargo, un gran fondo de verdad y de enseñanza: el carácter nacional. Digo de ensenanza, porque

28 Bach, Bellini, Haydn, Meyerber, Mozart, ete, son de familias de misticos; Carraceto, Murillo, Rafael, Van-Dyk de pintores; Aristófanes y Arioste de cómicos; Esquilo, Platón, Aristótéles, Taso, Milton, Racine, Corneille, Galleo, Bacon, Newton, Leibnitz, Byron, Schiller, Goethe, Linné, Cuvier, Hartkey, Humbold, Darwin, etc., son descendientes o engendraron hijos de distingaido talento, - El escritot ingles Galton en su célebre obra, Hereditarius Genius 1869, es quikn se ha ocupado especialmente, con gran erudición científica, de buscar comprobaciones histónicas de la herencia del genio. Véase tambićn, Lombroso: L'Homme de génie, trad, fran, de Coloma d'lstra, 1889. 
el carácter nacional es un descuidado. pero seguro guía, para aprectar la naturaleza y la dirección del movimiento social y político, del desarrollo artistico y cientifico del pueblo que refleja; para conocer el efecto que en él han de producir las leyes y las reformas; para saber todo lo que puede dar de sí en los solemnes momentos de peligro supremo. El carácter nacional, fijado por la herencia, es "la explicación última, la sola verdadera, de los vicios y de las virtudes de un pueblo, de su buena y de su mala fortuna". El nos sirve para distinguir al antiguo fenicio del griego, del romano, del galo. Por él, decimos, que el yanqui es atrevido, emprendedor, práctico e industrial; que el alemán, calmado, reflexivo, dado a profundas investigaciones científicas; que el francés es espiritual, ingenioso, cortés. de gran vivacidad. El señor Ribot, en su notable obra "La Herencia Psicológica", toma, con entera exactitud, como tipo de la eficaz acción de la herencia a dos pueblos: el judio y el bohemio ${ }^{29}$ : aquél el pueblo eminentemente religioso, avaro, desconfiado, caracterizándose por el predominio del sentimiento y la imaginación, que se manifiesta en sus obras religiosas. poéticas y musicales; éste refractorio a la civilización, sensual, vulgar. vagabundo, incapaz del trabajo, y dominado por el instinto irresistible hacia el robo; nosotros, a nuestra vez, podemos presentar el tipo de nuestro indio, humilde, perezoso, indiferente, reservado, tímido y servil.

La herencia psicológica en los individuos se explica cientificamente: El cuerpo humano, en su descomposición más simple, se halla constituido por unidades anatómicas microscópicas, dotadas de vida y actividad propia, que se llaman células ${ }^{30}$. Las células son los elementos rudimentarios, que luego al desarrollarse, forman los tejidos y los órganos. Ellos se transmiten por la generación, y, de la misma manera que las células pulmonares o hepáticas de los padres pasan a los hijos, lo mismo se efectúa con las células nerviosas que reaccionan sobre el cerebro. Ahora bien, por más idealista que sea la teoría que se profese respecto a la naturaleza de la inteligencia, tiene forzosamente que admitir todo hombre algo instruido, que el sistema cerebro-espinal, el cerebro, siendo el medio en que el pensamiento ejercita su acción, debe ejercer influencia en él, condicionando su naturaleza. Lo contrario seria ponerse en pugna con el principio cientifico de la acción del organismo físico sobre el moral, comprobado plenamente por el testimonio de la experiencia diaria. Imprimiendo, pues, las

\section{De la rasa tzingara.}

30 Van Beneden y Haeckel admiten un elemento más radimentario aủn que la cêlula, la cy toide, masa de sustancia albuminoides sin núcleo, ni envoltura. V. Haeckel: Psicologia celular, trad. esp. de la Bibt, esonómica filośfica, 1889 
células nerviosas un carácter especial a la actividad psiquica, y siendo ellas transmisibles: se comprende por tanto. fácilmente. cómo la ley biológica de la herencia puede aplicarse a la psicología.

Considerándola en sus efectos. Ia herencia es una fuerza conservadora: Cuando nuestros conocimientos nos enseñan, que un hombre adulto no conserva absolutamente ninguna de las células de su infancia, existiendo, sin embargo, la misma naturaleza y modo de ser del organismo en este transcurso del tiempo; la herencia nos lo explica, diciéndonos, que la célula madre, al desaparecer, deja grabado su carácter en la célula hija; estableciéndose así la encadenada armonia del organismo humano a través del tiempo. Pero la herencia no es sólo una fuerza conservadora, sino que también es una fuerza expansiva. En virtud de este principio, ella, en su acción, puede tomar dos diversas direcciones: o contribuye a la mayor vida y perfección del organismo: o su actividad es funesta, tendiendo a la depresión, menoscabo o aniquilamiento de él. En ambos casos despliega igual actividad; pero en aquélla su labor es positiva. en ésta negativa; en la primera se presenta como ley intensiva. en la segunda como ley decreciente. Estas dos diversas direcciones aplicadas a la psicologfa de los individuos, han servido paru dividir la herencia en normal y anormal; pero tales nombres no son propios, porque en ambos casos su acción es normal; la diferencia se marca, únicamente, por los efectos que produce, diversos según las circunstancias especiales en las que ella se ejercita. Por esto, la teoria novisima la divide, científicamente, en herencia intensiva y en herencia decreciente o mórbida ${ }^{31}$. En cuanto a lo primero, muchos ejemplos presenta la historia y la vida práctica de la transmisión de los caracteres, de aptitudes intelectuales, de sentimientos bondadosos, igualmente que de instintos repugnantes o perversos. El doctor Mausdley, en su obra "Patología de la inteligencia", hace la siguiente observación: "Yo he notado que cuando un hombre ha trabajado mucho para llegar de la pobreza a la riqueza, y para establecer sólidamente su familia, resulta en los descendientes una degeneración física y mental, que produce muchas veces la extinción de la familia en la tercera o cuarta generación. Cualquiera que sea la opinión de otros observadores experimentados, yo no puedo dejar de sostener que la excesiva pasión por la riqueza, absorviendo todas las fuerzas de la vida, predispone a una decadencia moral o inte-

31 En otro sentido b herencia poede clasificarse: ley de la herencia directa o indirecta; ley de preponderancia en la transmisión de los caracteres; ley de la herencia mediata, retroceso, atavismo; ley de la herencia en periodos correspondientes de la vida y herencia de inflaencia $V$ Ribot. obr. eit. 
lectual. 0 intelectual y moral a la vez". "Là herencia de la inclinación hacia el robo. dice Ribot. de quien tomo la cita anterior, está tan generalmente admitida. que es superfluo amontonar aqui hechos de que abundan todos los periódicos judiciales ${ }^{+32}$, La historia nos suministra también ejemplos de familias de héroes, de intrigantes y de tiranos.

Limitảndome a la herencia psicológica mórbida diré, que ella puede presentarse bajo dos maneras: como transmisión directa o de semejanza, y como transmisión transformada o metamorfoseada. Por la primera no sólo se hereda un gran número de enfermedades diatecsias, caquécticas y nerviosas, sino también afecciones mórbidas aisladas como el suicidio, homicidio, embriaguez, robo, etc. Respecto al impulso suicida hereditario, sobre el cual ya habia Voltaire llamado la atención de los médicos, cuenta Gall que siete hijos de un comerciante, que les habia dejado a su muerte dos millones, fortuna que ellos aumentaron, y sin experimentar ninguna desgracia; gozando de una buena salud, de una posición honrosa, de la consideración general, todos los siete hermanos en el intervalo de treinta a cuarenta años se suicidaron. El mismo Gall presenta otro caso de una familia en que la abuela, la madre y la hermana se suicidaron; la hija de esta última estuvo próxima a precipitarse, y eł hijo se ahorcó. Falret, en su obra sobre la hipocondría y el suicidio, cita el siguiente ejemplo: Un individuo se suicidó en su casa de París, su hermano, que acababa de asistir a sus funerales, al ver su cadáver exclamó: ¡Qué fatalidad! mi padre y mi tío se mataron, mi hermano les imita, y yo he tenido veinte veces la idea de arrojarme al Sena en mi viaje. Innumerables serian los ejemplos que pudiese añadir para manifestar la predisposición hereditaria hacia el suicidio en muchos casos, completamente independientes de la influencia perturbadora de las pasiones. ${ }^{33}$

Entre los casos de herencia de afecciones mórbidas, Gall, Lordat,

32 Ribot, L'hérédité etc. obra eitada. V. P. Lacas, Traité phikosophique et phisiologique de I" hérédizé naturelle, 1847.

33 Liske: Du suicide, statistique, médecine, histoire: legislation; 1859-Bertrand: Traité đu saicide considéné dans ses rapports aveo la philosophie, la theologiv, la médicine; 1857-Debreyne: Del suicidio considerado bajo los puntos de vista filośfico, religioso, moral y mb́dico; trad esp. anónims, 1857-Morel: Traité des malađies mentales: 1869 -Brierre de Boismot: Du suicide et đe la folie saicide; 2 a. Edición, 1863.

Un hecho muy triate, pero, por desgracia, bien comprobado, es el aumento progresiva de los suicidios en Europa: Asf, en Francia, de 1846 a 1857 su marcha es de 5 : 6, a 8, a 9, a 10 suicidios pot 100,000 habitantes. De 1871 a 1875 L difra se eleva a 11 , 212, a 13 y a 15 . Alcanza a 17 de 1876 a 1880 . En 1884 es el 29; se mantiene en 19 en 1885 para elevarse luego a 21 en $1886-V$. Joly: Le crime, 1888. 
Lucas y Ribot refieren el de una familia escocesi dominada por una tendencia instintiva hacia la antropofagia en muchas generaciones; familia de la cual varios miembros, habian pagado con su vida su perversa inclinación.

Pero, entre todos los ejemplos, el que más llama la atención es, como dice Foville, el de la familia Juke, cuyo nombre parece ha llegado a ser. en los Estados Unidos, sinónimo de criminal. Según los informes dados por Dugdalle sobre esta familia, -cuyo primer miembro conocido es un tal Max Juke, nacido por el ano 1720-, Lombroso ha formado una tabla genealógica que se extiende a siete generaciones, y que comprende 709 personas, entre las que 76 han sido condenados por haber cometido 115 delitos o crímenes. Sobre este mismo conjunto de 709 miembros conocidos de la familia Juke, se cuenta, por otra parte, 142 vagabundos, 129 prostituidos y 121 casos de enfermedades diversas ${ }^{34}$. Menos general, pero igualmente digno de tenerse en cuenta, es el de la genealogia de la familia Chrétien Lemaire, según el doctor Despine: Juan Chrétien, franco común, ha tenido tres hijos: Pedro, Tomás y Juan Bautista. I. Pedro tiene por hijo a Juan Francisco, condenado a trabajos forzados a perpetuidad por robo $\mathrm{y}$ asesinato. II. Tomás ha tenido: 1 . Francisco condenado a trabajos forzados por asesino; 2. Martín condenado a muerte por asesino. El hijo de este Martín murió en Cayenne condenado por robo. II. Juan Bautista tuvo por hijo a Juan Francisco, esposo de María Tanré de una familia de incendiarios. Este Juan Francisco tuvo siete hijos: 1, Juan Francisco. condenado por muchos robos, muerto en prisión; 2 . Benedicto que muere cayendo de un techo que escalaba; 3 . X... llamado Clam, condenado por diversos robos, muerto a los 25 años; 4 . María Reina, muerta en prisión, condenada por robo; 5. María Rosa, la misma suerte, los mismos actos: 6. Victor actualmente detenido por robo; 7. Victorina, esposa de Lemaire, cuyo hijo es condenado a muerte por asesinato y robo. ${ }^{35}$

La herencia mórbida no sólo obra de una manera directa, transmitiendo las mismas enfermedades o aberraciones morales, sino que ella, al ejercer su acción, comúnmente se transforma, se modifica, se metamorfosea. "Nosotros no entenderemos, exclusivamente, por herencia, dice el laureado Dr. Morel, la enfermedad misma del padre transmitida al hijo, con la identidad de los sintomas del orden físico y del orden moral observados en los ascendientes. Nosotros comprendemos bajo la palabra heren- 